\title{
Variation in the Obturator Vasculature During Routine Anatomy Dissection of a Cadaver
}

Vishwajit Deshmukh, "Seema Singh, Neerja Sirohi, Divya Baruhee

$$
\text { تباين الأوعية الدموية لعضلات المسد خلال عملية تشريح جثة روتيني }
$$

$$
\text { فيشواجت ديشموخ، سيما سينغ، نيرجا سيروحي، ديفيا باروحي }
$$

ABSTRACT: The obturator artery normally originates from the internal iliac artery while the obturator vein drains into the internal iliac vein. During a routine gross anatomy dissection class for undergraduate students at the All India Institute of Medical Sciences, New Delhi, India, in 2016, a rare unilateral variation in the obturator vasculature was found in a female cadaver of approximately 55 years of age. In this case, the left obturator artery originated from the superior gluteal artery and the left obturator vein drained into the external iliac vein. Knowledge of such variations is necessary during hernia procedures, ligation of the internal iliac artery and muscle graft surgeries.

Keywords: Iliac Artery; Anatomic Variation; Dissection; Case Report; India.

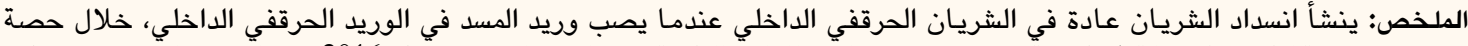

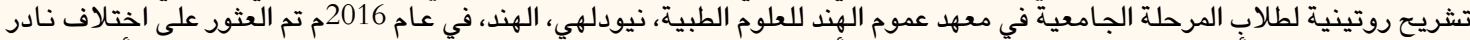

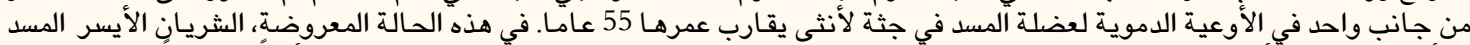

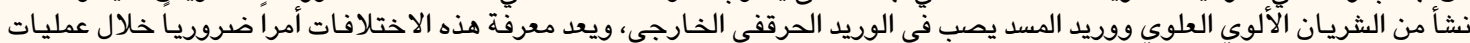

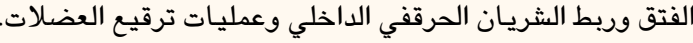

$$
\begin{aligned}
& \text { كلمات مفتاحية: الشريان الحرقفي؛ الإختلافات التشريحية؛ تشريح؛ تقرير حالة؛ الهند. }
\end{aligned}
$$

\section{$\mathrm{T}$}

He abdominal aorta divides into the right and left common iliac arteries which are anterolateral to the left side of the fourth lumbar vertebral body. Both of these arteries divide into the external and internal iliac arteries at the level of the sacroiliac joints. The external iliac artery mainly supplies blood to the lower limbs, whereas the internal iliac artery delivers the principal blood supply to the walls and viscera of the pelvis, perineum and gluteal region. ${ }^{1}$ The obturator artery is a mediumsized muscular artery which usually arises from the anterior trunk of the internal iliac artery. It then runs anterolaterally on the lateral pelvic wall and is crossed by the ureter at its medial aspect, before entering into the adductor compartment of the thigh after passing through the obturator canal. ${ }^{1}$

The obturator artery has a variable origin-sometimes it originates as a direct branch of the internal iliac artery and at other times from one of the other branches of the internal iliac artery, namely the superior gluteal, inferior epigastric and inferior gluteal arteries. ${ }^{2}$ The obturator artery provides the iliac branches to the iliac fossa and iliacus muscle. Occasionally, the obturator artery is replaced by an enlarged pubic branch of the inferior epigastric artery-an accessory obturator artery-which descends almost vertically to the obturator foramen. ${ }^{1}$ The obturator vein begins in the proximal adductor compartment and enters the pelvic cavity via the obturator foramen. It runs in a posterosuperior direction, below the obturator artery and between the ureter and internal iliac artery, before finally draining into the internal iliac vein. ${ }^{1}$ Anatomical knowledge of the pelvic viscera and the vasculature of the retropubic pelvic region is vital for endoscopic inguinal hernioplasties, laparoscopic herniorrhaphies and during bilateral internal iliac artery ligation, a life-saving procedure to control haemorrhage following complications in gynaecological and obstetric procedures. $^{3,4}$

\section{Case Report}

A routine educational gross anatomy dissection of a female cadaver of approximately 55 years of age was conducted at the All India Institute of Medical Sciences, New Delhi, India, in 2016. The cadaver had no pathological or traumatic lesions and there were no signs of any previous surgical procedures in the pelvic and perineal region. Both of the internal iliac arteries were divided at the level of the sacroiliac joints in front 


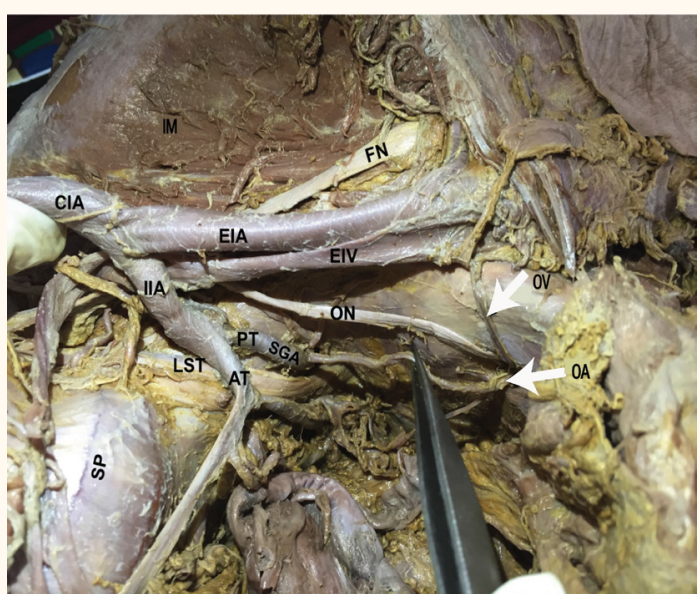

Figure 1: Photograph showing the abnormal origin and drainage pattern of obturator vessels on the left side of the pelvic wall of a female adult cadaver.

$I M=$ iliacus muscle; $F N=$ femoral nerve; $C I A=$ common iliac artery; EIA = external iliac artery; EIV = external iliac vein; $I I A=$ internal iliac artery; $O V=$ obturator vein; $O N=$ obturator nerve; $P T=$ posterior trunk; $S G A=$ superior gluteal artery; $L S T=$ lumbosacral trunk; $O A=$ obturator artery; $A T=$ anterior trunk; $S P=$ sacral promontory.

of the anterior margin of the greater sciatic notch and proceeded into the anterior and posterior trunk. The anterior trunk continued into the pelvis and supplied blood to the pelvic viscera through its branches. The posterior trunk divided into the iliolumbar, lateral sacral and superior gluteal arteries. The superior gluteal artery passed along the upper margin of the piriformis through the greater sciatic foramen.

The left obturator artery originated from the superior gluteal artery in the pelvic cavity and passed along the lateral pelvic wall to enter the obturator canal, below the obturator nerve. The left obturator vein, instead of draining normally into the internal iliac vein, drained into an external iliac vein and crossed the pelvic brim [Figure 1]. The right-sided anatomy of the obturator vasculature was normal, as were relations between the vasculature and obturator nerve in the obturator foramen and canal. No variations were observed in any of the other arteries, nerves or muscles.

\section{Discussion}

Anatomical knowledge of the obturator vasculature is important in surgeries related to the pelvic brim and the gluteal and adductor compartments of the thigh., ${ }^{3,4}$ The obturator artery chiefly supplies blood to the adductor compartment of the thigh as well as the smaller pelvic branches. Generally, the obturator artery originates from the anterior trunk of the internal iliac artery and follows the normal route along the lateral pelvic wall, to enter the thigh through the obturator canal. ${ }^{1}$ However, the origin of the obturator artery is highly variable. ${ }^{5}$ In a study of 50 cadavers, Rajive et al. found obturator arteries arising from various locations, including the common trunk of the internal iliac artery (4\%), anterior trunk of the internal iliac arteries (54\%), inferior epigastric artery (22\%), superior gluteal artery (2\%), internal pudendal trunk (2\%), inferior gluteal artery $(2 \%)$ and the external iliac artery $(4 \%){ }^{6}$ Bilgiç et al. reported a female newborn with a common arterial trunk arising from the medial side of the external iliac artery which subsequently divided into the obturator and inferior epigastric arteries. ${ }^{7}$

In more than one-third of cases, the anastomotic connection between the pubic branch of the inferior epigastric and obturator arteries can become enlarged; this is known as an "abnormal" obturator artery. ${ }^{8}$ Jusoh et al. reported that the origin of the obturator artery was the posterior division of the internal iliac artery in approximately $5.8 \%$ of cases and that this anomalous artery divided into an inferior vesical branch leading to the prostate. ${ }^{9}$ In the present case, the obturator artery originated from the superior gluteal artery on the left side and traversed the lateral pelvic wall along with the obturator nerve to enter the obturator canal. An abnormal origin of the obturator artery from the superior gluteal artery may have important surgical implications, particularly for female patients undergoing superior gluteal artery perforator flap surgery for breast augmentation/construction or to treat sacral pressure sores. ${ }^{10}$ Usually, veins in the pelvis and in the lower limbs follow the same course as the arteries; Nagabhooshana et al. reported a case wherein the obturator artery arose from the external iliac artery and the obturator vein drained into the external iliac vein, implying that the arteries were followed by the veins. ${ }^{11}$ However, in the present case, the artery arose from the superior gluteal artery while the left obturator vein drained into the external iliac vein and crossed the pelvic brim before termination. This type of vasculature may affect laparoscopic surgeries or open pelvic brim surgeries. ${ }^{3}$

The embryological basis for such variations in the vasculature of the limbs depends on the selection of the channels from the primary capillary plexus; the most appropriate channels will enlarge while others will retract and gradually disappear, thus establishing the final vascular pattern. ${ }^{12,13}$ Another explanation for abnormal vasculature could be angiogenesis as a result of hypoxia. ${ }^{14}$ Low oxygen saturation leads to the stabilisation of hypoxia-inducible factor 1- $\alpha$ which upregulates vascular endothelial growth factor A and nitric oxide synthase expression. Subsequently, the production of nitric oxide causes dilatation of the existing vessels and extravasation of plasma proteins, 
leading to protease and matrix metalloproteinase expression. ${ }^{14}$ These plasma proteins then play an important role in the proliferation and angiogenesis of endothelial cells which leads to the formation of abnormal vasculature. ${ }^{14}$ The obturator artery is formed relatively late during development, joining with an axial artery of the lower limb that accompanies the sciatic nerve. ${ }^{15}$ The origin of the obturator artery from the superior gluteal artery is due to the remains of the vascular channels related to the posterior trunk of the internal iliac arteries in circumstances where the vascular channels related to the anterior division predestined for the obturator artery may have degenerated. ${ }^{16}$

The obturator artery is an important source of collateral circulation for patients with aortoiliac and femoral arterial occlusive diseases. ${ }^{16}$ Femoral head ischaemia can sometimes occur due to decreased blood flow through the obturator artery due to trauma, a tumour or tuberculosis because of decreased blood flow through the branch of the obturator artery, which supplies blood to the femoral head via the ligamentum teres of the femur. ${ }^{16}$ During graft surgeries, additional advantage can be obtained in cases where the left obturator artery is longer than the right obturator artery, as with the present case. ${ }^{16}$

\section{Conclusion}

During a routine dissection of a female adult cadaver, a rare unilateral variation in the obturator vasculature was observed. The variation was found to lie in the origin of the obturator artery and termination of the obturator vein. Knowledge regarding potential variations in the obturator vasculature is important during pelvis and pelvic brim surgeries, particularly hernia surgeries. Furthermore, anatomical information regarding the obturator vasculature is also important when performing superior gluteal muscle grafts during breast augmentation surgeries in female patients. Documenting such variations is crucial and will help surgeons when considering various surgical approaches.

\section{References}

1. Borley NR. True pelvis, pelvic floor and perineum. In: Standring S. Gray's Anatomy: The anatomical basis of clinical practice, 40th ed. London, UK: Churchill Livingstone, 2008. Pp. 1083-98.

2. Pai MM, Krishnamurthy A, Prabhu LV, Pai MV, Kumar SA, Hadimani GA. Variability in the origin of the obturator artery. Clinics (Sao Paulo) 2009; 64:897-901. doi: 10.1590/S180759322009000900011.

3. Lau H, Lee F. A prospective endoscopic study of retropubic vascular anatomy in 121 patients undergoing endoscopic extraperitoneal inguinal hernioplasty. Surg Endosc 2003; 17:1376-9. doi: 10.1007/s00464-003-8800-y.

4. Havaldar PP, Taz S, Angadi AV, Saheb SH. Morphological study of obturator artery. Int J Anat Res, 2014; 2:354-7.

5. Pick JW, Anson BJ, Ashley FL. The origin of the obturator artery: A study of 640 body-halves. Am J Anat 1942; 70:317-43. doi: 10.1002/aja.1000700206.

6. Rajive AV, Pillay M. A study of variations in the origin of obturator artery and its clinical significance. J Clin Diagn Res 2015; 9:AC12-15. doi: 10.7860/JCDR/2015/14453.6387.

7. Bilgiç S, Sahin B. Rare arterial variation: A common trunk from the external iliac artery for the obturator, inferior epigastric and profunda femoris arteries. Surg Radiol Anat 1997; 19:45-7. doi: 10.1007/BF01627734

8. Basmajian JV. Grant's Method of Anatomy: By regions, descriptive and deductive, 8th ed. Philadelphia, Pennsylvania, USA: Williams \& Wilkins Co., 1971. Pp. 306-7.

9. Jusoh AR, Abd Rahman N, Abd Latiff A, Othman F, Das S, Abd Ghafar N, et al. The anomalous origin and branches of the obturator artery with its clinical implications. Rom J Morphol Embryol 2010; 51:163-6.

10. Mu LH, Yan YP, Luan J, Fan F, Li SK. [Anatomy study of superior and inferior gluteal artery perforator flap.] Zhonghua Zheng Xing Wai Ke Za Zhi 2005; 21:278-80.

11. Nagabhooshana S, Vollala VR, Rodrigues V, Bhat S, Pamidi N, Lobo SW. Anatomical variation of obturator vessels and its practical risk: A case report from an anatomic study. J Vasc Bras 2008; 7:275-7. doi: 10.1590/S1677-54492008000300015.

12. Arey LB. The development of peripheral blood vessels. In: Smith JL, Orbison DE, Eds. The Peripheral Blood Vessels. Baltimore, Maryland, USA: Williams \& Wilkins Co., 1963. Pp. 1-16.

13. Fitzgerald MJ. Human Embryology: A regional approach, 1st ed. New York, USA: Harpercollins College Div., 1978. Pp. 38-56.

14. Schoenwolf GC, Bleyl SB, Brauer PR, Francis-West PH. Larsen's Human Embryology, 4th ed. London, UK: Churchill Livingstone, 2008. Pp. 396-7.

15. Sañudo JR, Roig M, Rodriguez A, Ferreira B, Domenech JM. Rare origin of the obturator, inferior epigastric and medial circumflex femoral arteries from a common trunk. J Anat 1993; 183:161-3.

16. Kumar D, Rath G. Anomalous origin of obturator artery from the internal iliac artery. Int J Morphol 2007; 25:639-41. doi: $10.4067 /$ S0717-95022007000300028. 